\title{
FINANCIAMENTO PÚBLICO NO ESPORTE: OS REPASSES DO ES- TADO DE SANTA CATARINA PARA PROJETOS NA MESORREGIÃO GRANDE FLORIANÓPOLIS (2007-2014)
}

\author{
Ricardo Teixeira Quinaud \\ Universidade Federal de Santa Catarina, Florianópolis, Santa Catarina, Brasil. \\ Bárbara Schausteck de Almeida \\ Centro Universitário Internacional, Curitiba, Paraná, Brasil
}

\begin{abstract}
Resumo
Este artigo propõe uma leitura dos repasses do Fundo Estadual de Incentivo ao Esporte de Santa Catarina (FUNDESPORTE) para a mesorregião Grande Florianópolis. Mais especificamente, busca-se caracterizar a demanda de propostas submetidas e aprovadas com esses recursos, considerando sua divisão por ano, para os diferentes programas e para os tipos de entidades favorecidas, no período de 2007 a 2014. Em diálogo com a literatura nacional no assunto, destaca-se que: essa mesorregião é privilegiada, em comparação aos números populacionais e econômicos no estado; houve uma prioridade de submissão e maior volume de recursos para atletas ou equipes, infraestrutura e eventos; entidades privadas e pessoas físicas submetem mais propostas, sendo que essa demanda rege, até certo ponto, as finalidades dessa política.
\end{abstract}

Palavras-chave: Esportes. Políticas públicas. Financiamento.

\section{Introdução}

Nos anos 2000, Veronez (2005, p. 320) afirmava que "No universo acadêmico brasileiro, talvez não exista uma área de estudos tão pouco explorada por pesquisas científicas como a área do financiamento do esporte". Desde então, essa realidade mudou significativamente. Na última década, o financiamento do esporte, principalmente na perspectiva de investimento público federal, passou a ser um tema de interesse de pesquisadores, o que se traduziu em diversas publicações no formato de livro (BOUDENS, 2007), trabalho de conclusão de curso (SILVA, 2012), dissertação de mestrado (TEIXEIRA, 2016), teses de doutorado (ATHAYDE, 2014; CASTRO, 2016) e artigos científicos (ALMEIDA; MARCHI JÚNIOR, 2010; TEIXEIRA; MATIAS; MASCARENHAS, 2013; MATIAS et al., 2015; MASCARENHAS, 2017).

São indiscutíveis a relevância dessas produções e o crescimento das investigações nessa área, mas ainda é preciso avançar na compreensão do financiamento público do esporte no país, especialmente abordando as lógicas e tendências encontradas em estados e municípios. Com esse propósito, também houve um crescimento de produção na última década, com publicações, por exemplo, sobre o Acre (AZEVEDO, 2014), Bahia (SILVA; SANTANA; SILVA, 2015), Minas Gerais (CAMPOS, 2015) e Santa Catarina (QUINAUD, 2015; FURTADO et al., 2016; SOUZA, 2016), bem como sobre os municípios do estado de Minas Gerais (DI- 
NIZ; SILVA, 2016), de São Luís - MA (FERNANDES; BEZERRA, 2008) e Ponta Grossa PR (FRANÇA JUNIOR; FRASSONI; PILATTI, 2010). Sobre o estado de Santa Catarina, as produções cobriram a gestão de recursos na Secretaria de Estado de Turismo, Cultura e Esporte (SOL/SC) (QUINAUD, 2015; FURTADO et al., 2016) e, mais especificamente, o repasse de recursos aos atletas (SOUZA, 2016).

Embora existam particularidades locais quanto à legislação, às fontes de financiamento e aos programas, é possível e necessário estabelecer relações e comparações entre essas diferentes pesquisas, identificando se existem tendências comuns e se elas são comparáveis à realidade identificada em nível federal. No presente estudo, selecionamos as fontes de recursos financeiros do Fundo Estadual de Incentivo ao Esporte de Santa Catarina (FUNDESPORTE). O fundo, de acordo com a Lei ${ }^{\circ}$ 13.336, de 8 de março de 2005, é constituído a partir de recursos provenientes do Fundo de Desenvolvimento Social (FUNDOSOCIAL), de receitas decorrentes da aplicação desses recursos, de contribuições, de doações, de financiamentos, de investimentos de entidades públicas ou privadas, nacionais ou estrangeiras, da tributação de atividades lotéricas na forma da Lei $\mathrm{n}^{\circ} 11.348$, de 17 de janeiro de 2000, entre outros recursos que the venham a ser destinados (SANTA CATARINA, 2005).

A SOL/SC tem a missão de promover o desenvolvimento e a integração das atividades turísticas, culturais e esportivas no estado de Santa Catarina, visando à melhoria da qualidade de vida da população catarinense. Entre os anos de 2010 e 2014, a SOL/SC teve seis gestores na função de secretário estadual (MACÁRIO, 2014), indicando um significativo fracionamento político que pode interferir na implantação das políticas locais nas três áreas - turismo, esporte e cultura. Dentre as três diretorias que compõem a secretaria, destaca-se a Diretoria do Sistema de Incentivo a Turismo, Esporte e Cultura (SEITEC), responsável pela gestão dos fundos, abertura e execução dos programas, pelo acompanhamento do trâmite e repasse dos recursos, dentro dos limites orçamentários do estado. A SEITEC recebe, anualmente, a inscrição de propostas para obtenção de apoio financeiro dos Fundos Estadual de Incentivo à Cultura (FUNCULTURAL), ao Esporte (FUNDESPORTE) e ao Turismo (FUNTURISMO) (SANTA CATARINA, 2016).

Uma das ações da SOL/SC, mais recentemente regulamentada pelo Decreto $\mathrm{n}^{\circ} 1.309$, de 13 de dezembro de 2012, é o repasse de recursos para propostas submetidas por entidades públicas, privadas ou pessoas físicas. Esses repasses tiveram significativas variações descendentes anualmente, variando de R \$ 60 milhões em 2007 para menos de R \$ 2 milhões em 2014 (QUINAUD, 2015). Além disso, foi notável que, entre as seis mesorregiões políticas do estado (Norte, Sul, Oeste, Vale do Itajaí, Serrana e Grande Florianópolis), foi a mesorregião da Grande Florianópolis a mais privilegiada quanto ao recebimento desses recursos, alcançando quase $47 \%$ do total distribuído no período de 2007 a 2014. A mesorregião da Grande Florianópolis contempla 21 municípios, inclusive a capital catarinense, contando, em 2010, com uma população de 994.095 habitantes e um Produto Interno Bruto (PIB) de R \$ 20,68 bilhões (COSTA et al., 2013). Em perspectiva, é possível notar que o total distribuído em projetos esportivos é desproporcional, se considerarmos que a população naquele ano representava aproximadamente $16 \%$ do total e $13 \%$ do PIB do estado de Santa Catarina (SANTA CATARINA, 2017).

Desta maneira, este estudo propõe uma abordagem distinta das anteriores, com uma leitura mais específica sobre uma região que foi financeiramente mais privilegiada no repasse de recursos, qual seja, a mesorregião Grande Florianópolis. Assim, o problema de pesquisa é: qual a característica da demanda de propostas esportivas submetidas e aprovadas com recursos do FUNDESPORTE na região da Grande Florianópolis, considerando a divisão dos recursos por ano, para os diferentes programas e para os tipos de entidades favorecidas no período de 2007 a 2014 ? 


\section{Metodologia}

A presente pesquisa caracteriza-se como uma pesquisa documental, com abordagem quantitativa dos dados (DELGADO; MARIN, SÁNCHEZ, 2011), tendo como contexto investigativo informações fornecidas pela SOL/SC e limitando-se a uma comunidade, durante um determinado período temporal.

Fizeram parte da pesquisa todas as propostas esportivas submetidas diretamente ao FUNDESPORTE e que apresentavam as informações de programa esportivo de destino, verba destinada (caso aprovado), proponente, localidade e aprovação/reprovação descritas claramente nos documentos (critério de inclusão) durante o período de 2007-2014. Qualquer outra proposta submetida a outro fundo, mesmo que de cunho esportivo, não fez parte do estudo, bem como propostas com informações ausentes (critério de exclusão). Vale ressaltar que os proponentes são advindos de entidades públicas e privadas e de diferentes manifestações esportivas.

O levantamento das propostas esportivas foi autorizado pela Diretoria da SOL/SC, após apresentação dos objetivos e dos procedimentos investigativos. O acesso às fontes documentais foi disponibilizado nas instalações da SOL/SC, o que permitiu a análise individual das propostas cadastradas digitalmente em programas esportivos, cuja diversidade varia anualmente para contemplar as demandas existentes no âmbito do esporte de distintas mesorregiões do estado. A partir dessa catalogação, foram selecionadas as propostas submetidas que compunham a delimitação político-geográfica da Grande Florianópolis.

Para a definição das categorias de análise, foi utilizado o objeto de destino (o que ou quem receberia o financiamento) proposto pelos programas abertos pela SOL/SC, divididos em: (a) esportes de base e participação; (b) atletas ou equipes; (c) infraestrutura; (d) eventos, e (e) pesquisa científica/eventos científicos. Já as entidades proponentes foram separadas em entidades públicas, entidades privadas, pessoas físicas e federações. As pessoas físicas podem ser atletas ou representantes de equipes que solicitam recursos para a manutenção de suas atividades. Embora as federações também sejam entidades privadas, a opção pela separação em dois grupos distintos objetiva uma diferenciação mais específica do caráter e da finalidade neste grupo mais amplo.

A análise descritiva dos resultados quantitativos concentrou-se na frequência relativa e percentual dos recursos financeiros. Inicialmente, os dados foram organizados na planilha de cálculo no programa Excel, do sistema operacional Windows 10.

\section{O financiamento do esporte: do cenário nacional ao local}

Em nível federal, são diversas as leis que apontam para liberações e critérios de investimento de recursos de fontes públicas no esporte. Entre as mais significativas em vigor, destaca-se a Lei Pelé (Lei n ${ }^{\circ}$ 9615, de 1998), especialmente pelas alterações da lei conhecida como Agnelo-Piva, atualizada em 2015 (Lei no 13.146), que garante repasse das loterias para o Comitê Olímpico do Brasil, o Comitê Paralímpico Brasileiro e para a Confederação Brasileira de Clubes, bem como pelas Leis $\mathrm{n}^{\circ} 10.672$, de 2003, e $\mathrm{n}^{\circ} 13.155$, de 2015, que ditam no Art. $6^{\circ}$ da Lei Pelé quais as atuais fontes de recursos do Ministério do Esporte (BRASIL, 1998, 2003, 2015a, 2015b). Além do Art. 6 ${ }^{\circ}$, na mesma legislação, o Art. 56. prescreve que estados, o Distrito Federal (DF) e municípios assegurem em seus orçamentos recursos para fomento ao esporte, além de recursos das possíveis fontes: "I - fundos desportivos; II - receitas oriundas de concursos de prognósticos; III - doações, patrocínios e legados; IV - prêmios de concursos de prognósticos da Loteria Esportiva Federal não reclamados nos prazos regulamentares; V incentivos fiscais previstos em lei [...]" (BRASIL, 1998). Do parágrafo V, destacamos a cha- 
mada Lei de Incentivo ao Esporte (Lei ${ }^{\circ} 11.438$, de 2006), que permite o investimento de parte do Imposto de Renda em projetos esportivos (BRASIL, 2006).

Considerando essas distintas fontes de recursos públicos para o esporte, Mascarenhas (2017) propõe uma classificação, conforme a origem dos recursos. Assim, teríamos as fontes orçamentárias (especialmente recursos do Ministério do Esporte e das loterias, que fazem parte do orçamento federal), fontes extraorçamentárias (repasse das loterias para as instituições esportivas e patrocínios de estatais, que sequer chegam ao orçamento federal) e fontes indiretas (isenção de pagamento de impostos, que também não chegam ao orçamento federal).

A partir da referência federal, os estados, o Distrito Federal (DF) e os municípios têm autonomia na criação de leis complementares, sendo esse um direito previsto na Constituição Federal de 1988. Dada a adoção do federalismo como forma de organização territorial do poder no Brasil, os capítulos II ao IV da Constituição prescrevem que cada ente tem sua autonomia, ao mesmo tempo em que tem competências a serem atendidas. Essas competências dependem da área, podendo ser exclusivas, concorrentes e comuns (BRASIL, 1988). No caso do esporte, assim como educação, cultura, ciência e tecnologia, a Constituição indica que União, Estados e o DF podem legislar concorrentemente. Ou seja, a União deve estabelecer normas gerais, enquanto Estados e o DF estabelecem normas particulares, já que a indicação para legislar concorrentemente prescreve que esses entes devem legislar sobre esse tema (repartição vertical), em oposição à divisão dos temas que deve ser responsabilidade de cada um (repartição horizontal - competência comuns ou privativas) (FERRAZ JÚNIOR, 1995). No caso dos municípios, a Constituição indica somente a possibilidade de criação de leis suplementares.

Como o próprio nome da competência indica, estabelece-se uma ação concorrente não só na legislação, mas também na implementação de programas e ações, como consequência. Enquanto algumas áreas dentro do esporte tendem a ser privilegiadas por mais de um ente, outras podem ficar desassistidas, deixando lacunas na cobertura dos serviços públicos. Especialmente nos níveis mais locais (municípios e estados), os programas e as ações parecem ser variáveis de acordo com preferências políticas (STAREPRAVO et al., 2006) e, na necessidade de priorizar uma área em detrimento de outra pela limitação financeira, essas lacunas podem ser ainda mais significativas.

No caso do estado de Santa Catarina, pode-se dizer que conta com políticas públicas com características curiosas e peculiares. De acordo com Vaz (2001), o financiamento não se trata simplesmente de gerenciar recursos, mas deve desenvolver outra cultura que esteja incorporada na dinâmica das cidades. Uma das características do estado é a participação de empresas privadas no financiamento de projetos esportivos, especialmente por meio da já mencionada lei federal de incentivo ao esporte. Além disso, também dispõem de orçamentos com recursos próprios para o financiamento de projetos que não se enquadrem em leis de incentivo fiscal, sendo mais um canal de comunicação com a população (ALVES, 2009).

Relacionado ao financiamento público, os dois estudos realizados na FUNDESPORTE de Santa Catarina, sobre o financiamento de atletas e os financiamentos aos programas da SOL/SC, mostraram decréscimo no financiamento ao longo dos anos e elevado financiamento à mesorregião da Grande Florianópolis, totalizando mais de $65 \%$ do total de verba distribuída a atletas e aproximadamente $47 \%$ da distribuição aos programas esportivos (SOUZA, 2016; QUINAUD, 2015). Não é somente no esporte que os repasses e o financiamento estadual são mais elevados na mesorregião da Grande Florianópolis. Também foi verificada elevada concentração de financiamento público pela Secretaria de Estado de Planejamento nesta mesorregião, podendo estar relacionada à sua capacidade de articulação política e a seus melhores índices de desenvolvimento econômico (RUDNICK; MATTEDI, 2013).

À parte do financiamento ao esporte através do FUNDESPORTE, ainda não foram publicados dados consolidados das demais ações (especialmente as orçamentárias) do período 
que permitam indicar a proporção ou a relevância financeira dos recursos aprovados pelo fundo em comparação com outras políticas esportivas estaduais, o que poderia indicar sua necessidade e sua efetividade durante o período aqui em análise. Vale ressaltar que o governo do estado de Santa Catarina tem como projetos esportivos próprios as competições estaduais, que são organizadas pela Fundação Catarinense de Esporte (FESPORTE). Avaliações dessa natureza permitiriam um melhor conhecimento do cenário histórico da região, para que as intervenções de financiamento garantissem o adequado desenvolvimento futuro (CHRISTENSEN et al., 2007).

\section{Resultados}

Conforme exposto no problema de pesquisa, nesta seção é descrita a característica da demanda das propostas esportivas submetidas e aprovadas para recebimento de recursos do FUNDESPORTE na região da Grande Florianópolis entre 2007 e 2014, considerando a divisão dos recursos por ano, para os diferentes programas e para os tipos de entidades favorecidas.

No que se refere à distribuição de verba durante os anos investigados proveniente da SOL/SC, verifica-se uma queda significativa e recorrente ao longo dos anos analisados, tanto nos montantes totais do estado quanto para a mesorregião da Grande Florianópolis. Mesmo com essas quedas, a mesorregião da Grande Florianópolis concentrou 46,9\% do total de verba distribuída a todo o estado no período, totalizando $\mathrm{R} \$ 235,8$ milhões. Dessa captação para a região, nota-se que as variações percentuais também são significativas e erráticas. Em 2012 e 2013, a concentração de recursos caiu de $66,2 \%$ para $12,1 \%$ (Figura 1), o que indica uma provável ausência de parâmetros ou de metas de distribuição regional dos recursos.

Figura 1- Distribuição de verba entre os anos de 2007-2014 na mesorregião da Grande Florianópolis de Santa Catarina.

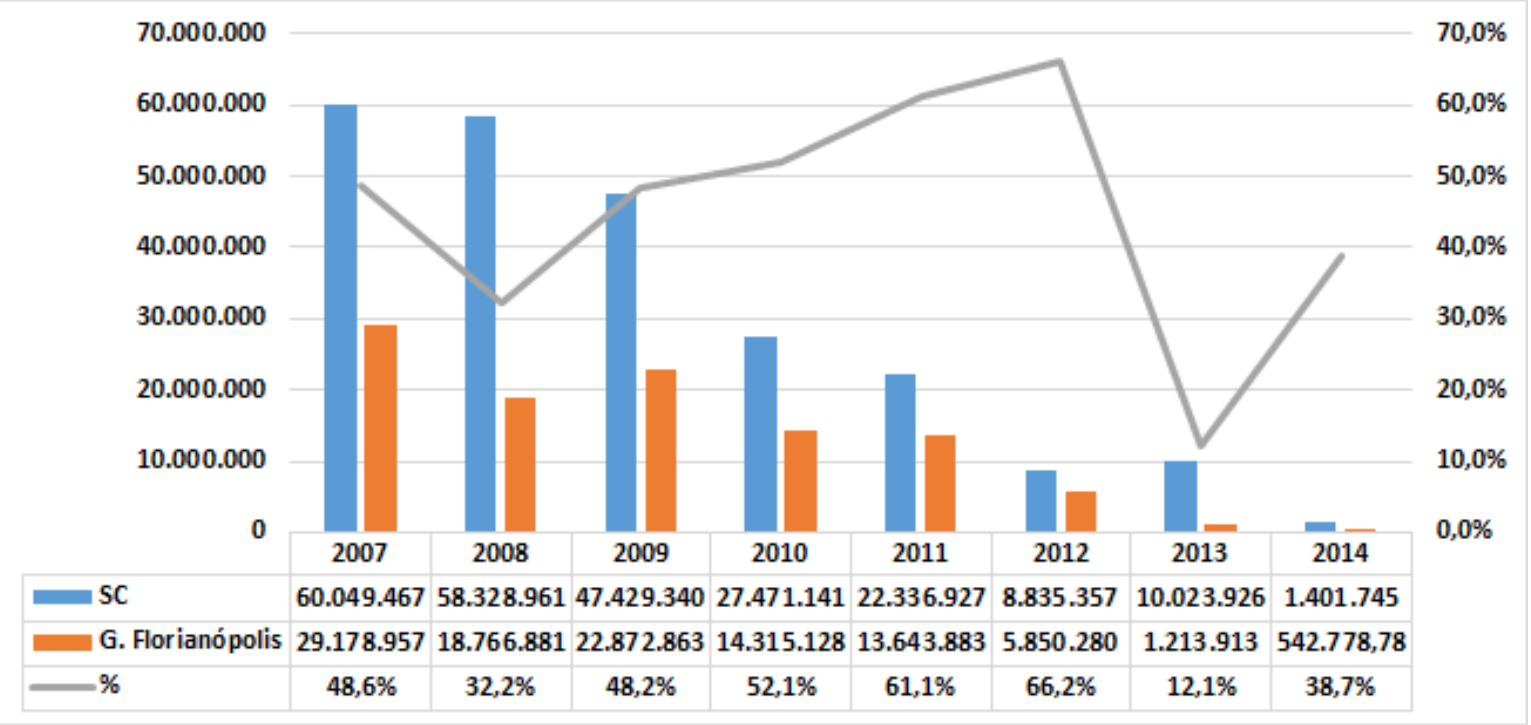

Fonte: Elaborado pelos autores, 2017.

Embora os outros estudos publicados não tenham identificado uma queda progressiva nos recursos, como neste caso, quando analisam um intervalo temporal mais longo, é comum a observação de que os recursos financeiros para as áreas de esporte e lazer tendem a ser irregulares, sem seguir um padrão que permita um planejamento de maior prazo e diretrizes claras quanto aos propósitos das políticas (CAMPOS, 2015; SILVA; SANTANA; SILVA, 2015). As publicações de outros estados e municípios não trazem dados quantitativos sobre 
recursos dos fundos, mas de outros tipos de fontes orçamentárias e não orçamentárias, o que inviabiliza comparações acerca dos montantes aqui encontrados.

Os dados da Figura 1 precisam ser vistos em comparação com o número de propostas submetidas por essa mesorregião, porque o alto ou o baixo índice de aprovação pode ter relação direta com a alta ou a baixa submissão de propostas em cada um dos anos. Neste aspecto, que também permite indicar o percentual de aprovação das propostas, verifica-se flutuação ao longo dos anos, com variação de 60 propostas submetidas em 2014 até 326 em 2012, como também nos percentuais de aprovação, que variam de 19,3\% em 2012 até 56,8\% em 2009. Em diálogo com os dados apresentados na Figura 1, verificamos que 2012 foi o ano com mais propostas, com menor aprovação em número de propostas, mas com mais significativo percentual de recursos aprovados na mesorregião em comparação ao estado (Figura 2). Porém, esses dados precisam ser vistos em comparação com o montante que estava disponível pelo estado, que foi muito menor que os anos anteriores. $\mathrm{O}$ número total de propostas esportivas submetidas por todo o estado em todo o período foi 5.704, sendo 32,6\% apenas da mesorregião da Grande Florianópolis. Além disso, o número total de propostas aprovadas pelo estado foi de 1.973, sendo 37\% apenas na Grande Florianópolis.

Figura 2 - Número de propostas enviadas entre os anos de 2007-2014 e percentual de aprovação na mesorregião da Grande Florianópolis de Santa Catarina.

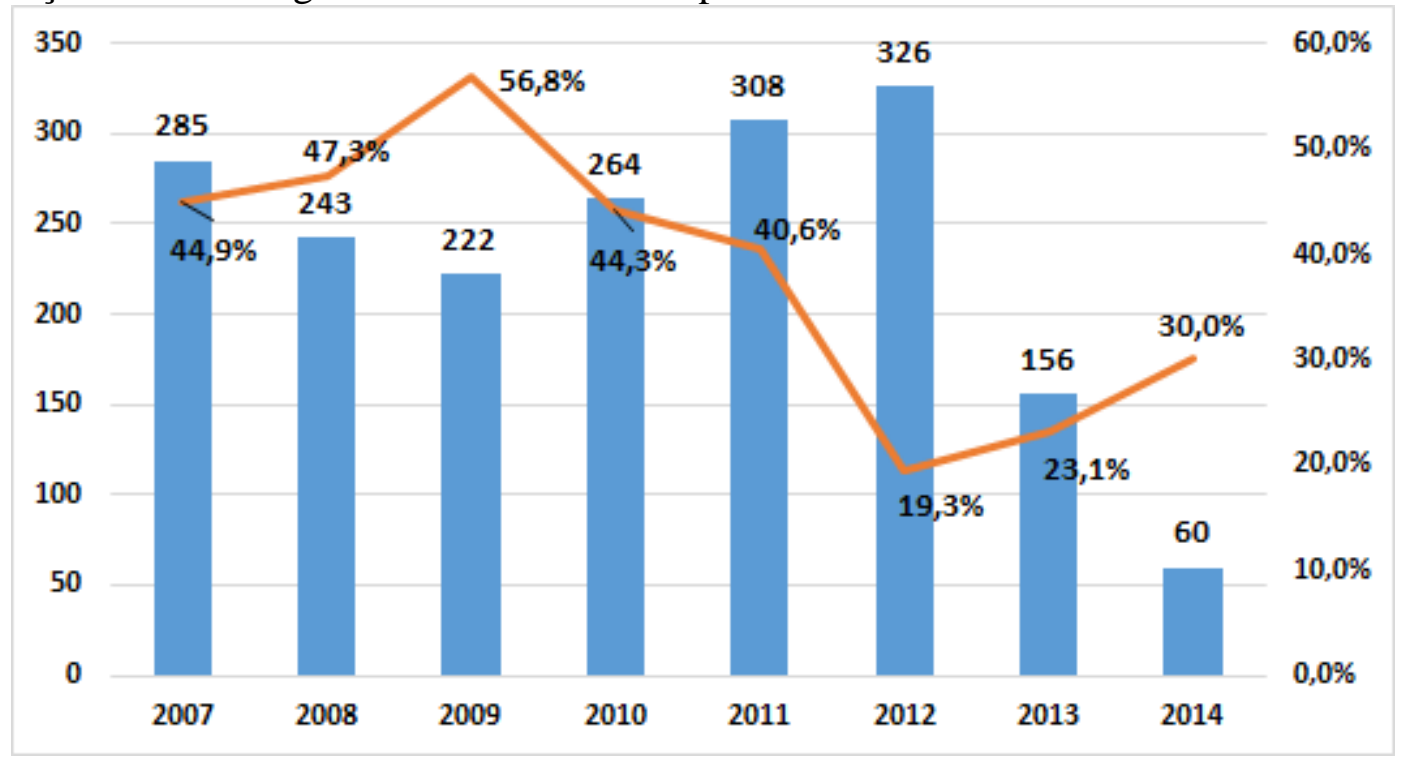

Fonte: Elaborado pelos autores, 2017.

Para a análise desse aspecto, podemos estabelecer paralelos com as discussões realizadas sobre as leis de incentivo ao esporte, pois se trata da submissão de propostas por entes públicos e privados, a serem aprovadas por um ente público, para ter acesso aos recursos. Por um lado, podemos ver semelhança na tendência segundo a qual é preciso conhecimento técnico e pessoal capacitado para a adequação do projeto às demandas da legislação - o que também foi observado no caso do ICMS esportivo em Minas Gerais (DINIZ; SILVA, 2016) -, assim como, em certo sentido, uma terceirização da implementação das políticas, o que coloca em dúvida se há a aplicação das diretrizes planejadas (FERNANDES; BEZERRA, 2008; FRANÇA JUNIOR; FRASSON; PILATTI, 2010; MATIAS et al., 2015). Por outro lado, a diferença está no fato de que não há a necessidade de captação de recursos através da iniciativa privada, que aceitaria liberar parte de seus impostos para a aplicação no projeto aprovado, o que elimina uma etapa que parece ser impeditiva para muitos projetos terem acesso ao re- 
curso (MATIAS et al., 2015). Nesse sentido, a aprovação de projetos no FUNDESPORTE é um grande facilitador para instituições públicas e privadas terem acesso aos recursos públicos.

Outro elemento crítico no financiamento do esporte, que é observado nesta análise, está relacionado à distribuição entre os programas para as diferentes manifestações do esporte. No quantitativo de propostas submetidas, primeiramente observa-se a elevada submissão de propostas relacionadas a atletas ou a equipes, bem como para eventos esportivos, que concentram 75,5\% das submissões da mesorregião. A abertura de acesso a recursos do fundo para pessoas físicas facilita a construção desse cenário. Na sequência quantitativa de propostas submetidas, estão infraestrutura, esporte de base e participação e pesquisa/eventos científicos. Já o percentual de aprovação também é superior para atletas e equipes, seguido por infraestrutura e eventos, como evidenciado na Figura 3.

Figura 3 - Número de propostas enviadas e percentual de aprovação de acordo com o programa de destino da mesorregião da Grande Florianópolis de Santa Catarina.

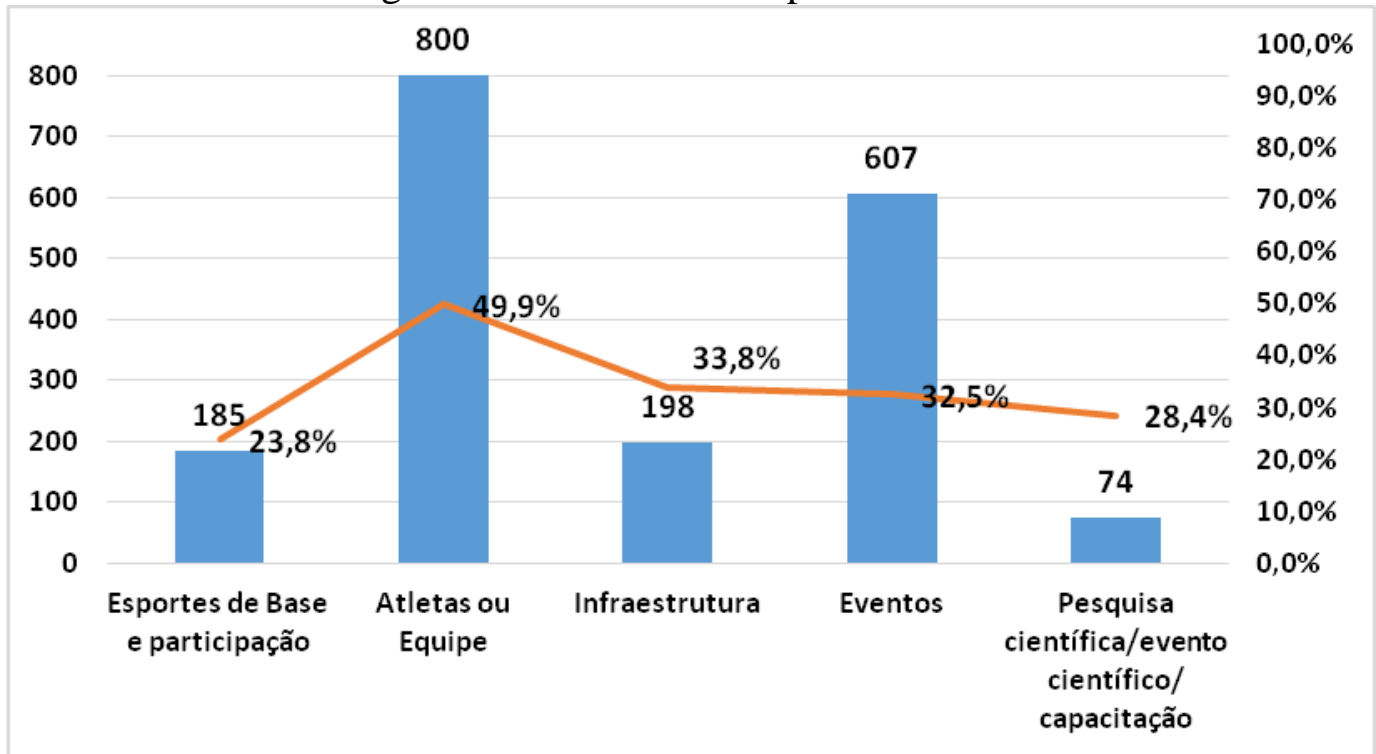

Fonte: Elaborado pelos autores, 2017.

A realidade observada na quantidade de propostas submetidas e aprovadas, a partir dos diferentes programas, também pode ser pensada sobre a necessidade de um corpo técnico capacitado para a elaboração das propostas, ainda que não existam evidências explícitas sobre as razões para as aprovações e reprovações. Esses dados também precisam ser vistos a partir das variáveis financeiras para uma mais adequada avaliação.

Apesar de o programa de atletas ou equipes ter maior número de propostas submetidas e maior percentual de aprovação, isso não se reflete na posição quanto ao acesso aos maiores recursos. No caso da mesorregião da Grande Florianópolis, foram os eventos que receberam a maior destinação de recursos financeiros, seguidos de infraestrutura. No total do estado, essas posições se invertem. Além disso, uma característica de destaque da mesorregião é sua concentração de recursos financeiros nos programas de pesquisa científica (quase $95 \%$ da verba), eventos e atletas e equipes (acima de 50\%), conforme pode ser visto na Figura 4. 
Figura 4 - Repasses de recursos financeiros a Santa Catarina e Grande Florianópolis de acordo com o programa de destino e seus respectivos percentuais de aprovação.

\begin{tabular}{|c|c|c|c|c|c|c|}
\hline \multirow[t]{2}{*}{$\begin{array}{r}100.000 .000 \\
90.000 .000 \\
80.000 .000 \\
70.000 .000 \\
60.000 .000 \\
50.000 .000 \\
40.000 .000 \\
30.000 .000 \\
20.000 .000 \\
10.000 .000 \\
0\end{array}$} & & & & & & \multirow[t]{5}{*}{$\begin{array}{l}100,0 \% \\
90,0 \% \\
80,0 \% \\
70,0 \% \\
60,0 \% \\
50,0 \% \\
40,0 \% \\
30,0 \% \\
20,0 \% \\
10,0 \% \\
0,0 \%\end{array}$} \\
\hline & $\begin{array}{c}\text { Esportes de } \\
\text { Base e } \\
\text { participação }\end{array}$ & $\begin{array}{c}\text { Atletas ou } \\
\text { Equipe }\end{array}$ & Infraestrutura & Eventos & $\begin{array}{c}\text { Pesquisa } \\
\text { científica/eve } \\
\text { nto científico/ } \\
\text { capacitação }\end{array}$ & \\
\hline SC & 10.639 .470 & 46.108 .741 & 93.474 .771 & 81.978 .468 & 3.675 .415 & \\
\hline G. Florianópolis & 4.730 .670 & 23.578 .557 & 29.964 .998 & 48.672 .432 & 3.488 .025 & \\
\hline$\%$ & $44,5 \%$ & $51,1 \%$ & $32,1 \%$ & $59,4 \%$ & $94,9 \%$ & \\
\hline
\end{tabular}

Fonte: Elaborado pelos autores, 2017.

O repasse mais significativo de recursos, no estado de Santa Catarina, para infraestrutura esportiva reforça uma tendência observada no governo federal nos últimos anos, especialmente a partir das emendas parlamentares (CASTRO, 2016; TEIXEIRA, 2016), como também no estado da Bahia (SILVA; SANTANA; SILVA, 2015). É possível levantar a hipótese que isso não se refletiu na mesorregião da Grande Florianópolis em razão de uma maior presença de infraestrutura já existente na região, considerando sua centralidade política, ainda que um montante de quase $\mathrm{R} \$ 30$ milhões continue sendo significativo. O foco nos eventos também foi observado por Fernandes e Bezerra (2008), Silva, Santana e Silva (2015) e Diniz e Silva (2016), o que talvez possa ser visto como uma estratégia de aumento no número de pessoas atendidas por administrações locais (FERNANDES; BEZERRA, 2008).

Para melhor compreensão da concentração dos recursos financeiros na mesorregião da Grande Florianópolis, foram verificados os valores mínimos e máximos das propostas aprovadas da Grande Florianópolis em comparação com o estado de Santa Catarina. A Tabela 1 evidencia que as propostas aprovadas para a mesorregião em análise apresentam valores mínimos mais elevados em comparação àqueles do estado, com exceção do programa de atletas ou equipes, que exibe o mesmo valor. No caso dos valores máximos, é evidente que a mesorregião concentra os maiores valores financeiros, com única exceção do programa de eventos. Em outras palavras, as propostas aprovadas na Grande Florianópolis tendem a receber mais recursos que outras propostas, sendo que nesta mesorregião estiveram as propostas aprovadas com os maiores recursos para programas de infraestrutura, atletas ou equipes, esportes de base e participação e pesquisa científica/evento científico. 
Tabela 1 - Comparação de valores máximos e mínimos das propostas aprovadas entre Santa Catarina e Grande Florianópolis, de acordo com o programa de destino.

\begin{tabular}{|l|l|l|l|l|}
\hline \multicolumn{2}{l}{} & \multicolumn{2}{l|}{ Santa Catarina } & \multicolumn{2}{l|}{ Grande Florianópolis } \\
\hline Categorias & Mínimo $(\mathrm{R} \$)$ & Máximo $(\mathrm{R} \$)$ & Mínimo $(\mathrm{R} \$)$ & Máximo $(\mathrm{R} \$)$ \\
\hline $\begin{array}{l}\text { Esportes de base e participa- } \\
\text { ção }\end{array}$ & $7.700,00$ & $350.000,00$ & $16.000,00$ & $350.000,00$ \\
\hline Atletas ou equipes & $2.000,00$ & $1.500 .000,00$ & $2.000,00$ & $1.500 .000,00$ \\
\hline Infraestrutura & $1.000,00$ & $6.941 .000,00$ & $12.100,00$ & $6.941 .000,00$ \\
\hline Eventos & $6.000,00$ & $4.000 .000,00$ & $7.990,00$ & $2.000 .000,00$ \\
\hline $\begin{array}{l}\text { Pesquisa científica/ evento } \\
\text { científico/ capacitação }\end{array}$ & $15.000,00$ & $400.000,00$ & $15.000,00$ & $400.000,00$ \\
\hline
\end{tabular}

Fonte: Elaborado pelos autores, 2017.

Dialogando com os dados apresentados anteriormente, é possível confirmar que a quantidade de propostas submetidas e aprovadas foi maior para atletas ou equipes, mas que isso não se reflete no montante financeiro, especialmente considerando que o valor máximo aprovado é muito menor que para infraestrutura e eventos. De fato, essas diferenças são compreensíveis, inclusive levando-se em conta a possibilidade de aprovar um maior número de projetos no total quando o investimento financeiro não é tão alto. Para discutir as demandas e prioridades nas propostas para acesso aos recursos financeiros do FUNDESPORTE, é possível indicar que atletas ou equipes têm maior quantidade de propostas submetidas e maior aprovação, terceiro maior montante de recursos recebidos e terceiro programa com proposta de maior valor aprovada. Eventos estão na segunda posição em todos esses quesitos, exceto no número de propostas aprovadas, enquanto infraestrutura é o primeiro nos montantes financeiros, terceiro no número de propostas e segundo no número de propostas aprovadas. Por esses posicionamentos, é possível perceber que a demanda da mesorregião da Grande Florianópolis, para os recursos do FUNDESPORTE, está assim caracterizada.

Ao ser analisado o tipo de proponente de destino das propostas esportivas, o setor privado foi o que teve maior número de submissões e o terceiro maior percentual de aprovação. Em contrapartida, o setor público obteve o menor percentual de aprovação e o maior valor recebido de uma proposta, sendo este valor mais de três vezes maior do que qualquer outro. Vale ressaltar que o proponente denominado pessoa física obteve o maior percentual de aprovação, seguido das federações esportivas, conforme explicitado na Tabela 2.

Tabela 2 - Análise das propostas esportivas considerando o tipo de proponente.

\begin{tabular}{|l|l|l|l|l|}
\hline $\begin{array}{l}\text { Tipo de propo- } \\
\text { nente }\end{array}$ & $\begin{array}{l}\text { Número de pro- } \\
\text { postas }\end{array}$ & $\begin{array}{l}\text { Percentual de } \\
\text { aprovação }\end{array}$ & Valor mínimo $(\mathbf{R} \mathbf{)})$ & $\begin{array}{l}\text { Valor máximo } \\
(\mathbf{R} \$)\end{array}$ \\
\hline Privado & 833 & $32,7 \%$ & $17.146,92$ & $1.500 .000,00$ \\
\hline Público & 175 & $25,0 \%$ & $7.990,00$ & $6.941 .000,00$ \\
\hline Pessoa Física & 505 & $48,5 \%$ & $2.000,00$ & $247.990,70$ \\
\hline Federação & 350 & $48,3 \%$ & $30.000,00$ & $2.000 .000,00$ \\
\hline
\end{tabular}

Fonte: Elaborado pelos autores, 2017.

Mesmo que o percentual de aprovação seja menor para proponentes privados em comparação às pessoas físicas e à federação, o número de propostas aprovadas ainda assim é o maior entre todos os tipos de proponentes. Retomando os possíveis paralelos feitos com a Lei de Incentivo ao Esporte, aqui é possível pensar se entidades privadas têm mais profissionais aptos para submeter as propostas, a ponto de alcançar um número majoritário de envios. Ainda, é possível observar que proponentes privados (entidades e federações esportivas) confiam 
nesse meio de acesso ao fundo público. Mesmo que as propostas estejam sujeitas à aprovação, aqui também é questionável se as ações de fato têm uma finalidade pública, se estão consonantes com os objetivos indicados pelos planejamentos dos entes públicos e se promovem o direito ao esporte, como previsto na Constituição Federal (MATIAS et al., 2015). A partir desses argumentos, é preciso questionar se essa estratégia de política pública atende, de fato, aos interesses dos cidadãos catarinenses e da mesorregião da Grande Florianópolis no acesso às práticas esportivas.

\section{Considerações finais}

A caracterização das propostas submetidas e aprovadas à SOL/SC para acesso a recursos do FUNDESPORTE na mesorregião Grande Florianópolis confirmam algumas das tendências e preocupações demonstradas em pesquisas anteriores sobre o financiamento público do esporte. Também aqui houve um investimento significativo para a infraestrutura esportiva, como se observa no cenário federal, mas também uma prioridade em eventos e em atletas ou equipes, como se observa em pesquisas de níveis estaduais e municipais. Como um diferencial, o destaque esteve no fato de se observar a participação de uma mesorregião no financiamento do esporte estadual, tanto no que se confirma das tendências estaduais quanto no que se diferencia, especialmente sobre o destaque e a relevância da mesorregião. A partir da consolidação dos dados, com o suporte em informações oficiais, tem-se que a mesorregião Grande Florianópolis representa $16 \%$ da população de Santa Catarina, 13\% do PIB, submeteu 32,6\% das propostas, teve $37 \%$ das propostas aprovadas e $46 \%$ dos recursos disponibilizados, mostrando um desequilíbrio quantitativo, se este fosse o único critério para consideração. Pelo fato de a capital do estado, Florianópolis, estar localizada nesta mesorregião do estado, fatores econômicos e políticos podem estar associados aos dados encontrados nesta pesquisa, entretanto, nenhuma afirmação pode ser totalmente confirmada pela metodologia eleita para este momento.

Pela análise não só dos valores aprovados, mas também das características das propostas submetidas, foi possível verificar que há um atendimento de demanda, que acaba por priorizar alguns programas em detrimento de outros. Este é um ponto central quando se analisam propostas de políticas públicas que atendem somente aos grupos proativos, informados e organizados, capazes de cumprir com as exigências da legislação. Sobre este aspecto, fizemos paralelos com os debates nacionais sobre a Lei de Incentivo ao Esporte, que encontra semelhanças com o caso em pauta.

Outra leitura recorrente nos estudos de financiamento do esporte se dá sobre a prioridade do alto rendimento em comparação ao esporte educacional e à participação, ainda que essas comparações sejam dificultadas quando o investimento em infraestrutura e eventos estão incluídos, já que normalmente não há especificação sobre qual manifestação esportiva é o destino final dessas ações e construções. Outro ponto crítico é o fato de que algumas propostas, projetos e políticas caracterizam como esporte educacional a formação esportiva através de escolinhas de esporte, o que demandaria estudos mais específicos nas ações para essa categorização. Por essas limitações, não é possível uma assertividade sobre qual manifestação esportiva foi priorizada, ainda que o tripé atleta-infraestrutura-evento tenha tido preferência na aprovação e na distribuição de recursos, tanto em nível estadual quanto na mesorregião da Grande Florianópolis, mesmo com o decréscimo de investimentos.

Apesar das limitações encontradas, principalmente no que diz respeito ao desconhecimento do motivo das reprovações das propostas esportivas e da necessidade de maior diálogo com informações que não são ou estão disponíveis em fontes documentais, esta pesquisa contribui para a discussão do financiamento e das políticas públicas para o esporte, no sentido de indicar, na dinâmica estadual-mesorregional, indícios que se assemelham a outras realida- 
des estaduais e municipais. Aqui se reforça a necessidade de revisão das políticas nacionais, estaduais e locais para que atuem em um sentido mais complementar, evitando a sobreposição de ações, por um lado, e, por outro, o não atendimento a outras manifestações do esporte.

\title{
PUBLIC FUNDING IN SPORT: THE STATE OF SANTA CATARINA TRANSFERS TO PROJECTS IN THE MESOREGION OF GRANDE FLORIANÓPOLIS (2007- 2014)
}

\begin{abstract}
This article proposes an interpretation on the transferrings from the Santa Catarina state sport fund (FUNDESPORTE) to the mesoregion of Grande Florianópolis. Especifically, it characterizes the demand on the submitted and approved proposals, considering the division by year, according to the different programs and the types of organizations between 2007 and 2014 . Through a dialogue with the Brazilian literature, it is highlighted: the mesoregion is privileged statewise, compared to its population and economy; higher demand on proposals and more resources were given to athletes or teams, facilities and events; private organizations and individuals sent more proposals, whereas this demand rules the objectives of this policy.

Keywords: Sports. Public policy. Funding.

\section{FINANCIACIÓN PÚBLICA DEL DEPORTE: LAS TRANSFERENCIAS DEL ESTA- DO DE SANTA CATARINA PARA PROYECTOS EN LA MESORREGIÓN GRANDE FLORIANÓPOLIS (2007-2014)}

\begin{abstract}
Resumen
El artículo propone una lectura de los envíos de recursos desde el fundo de deporte del estado de Santa Catarina (FUNDESPORTE) para la mesorregión Grande Florianópolis. Específicamente, él caracteriza la demanda de propuestas sometidas y aprobadas, considerando la división por año, por los distintos programas y por los tipos de organizaciones de 2007 hasta 2014. En un diálogo con la literatura brasileña, se resalta: esa mesorregión es privilegiada en comparación con su población y economía en el estado; hay una mayor demanda de propuestas y más recursos son enviados para atletas o equipos, infraestructura y eventos; organizaciones privadas e individuos envían más propuestas, las cuales reglan los objetivos de la política. Palabras clave: Deportes. Políticas públicas. Financiación.
\end{abstract}

\section{Referências}

ALMEIDA, B. S. de; MARCHI JÚNIOR, W. O financiamento dos programas federais de esporte e lazer no Brasil (2004 a 2008). Movimento, v. 16, n. 4, p. 73-92, out./dez. 2010.

ALVES, K. S. Marketing cultural e o patrocínio próprio e incentivado da cultura em Santa Catarina: análise dos casos Eletrosul e Tractebel energia. 2009. 126 f. Dissertação (Mestrado) - Universidade Federal de Santa Catarina, Florianópolis, 2009.

ATHAYDE, P. F. A. O ornitorrinco de chuteiras: determinantes econômicos da política de esporte e lazer do governo Lula e suas implicações sociais. 2014. 192 f. Tese (Doutorado em Política Social) - Universidade de Brasília, Brasília, 2014. 
AZEVEDO, J. R. C. de. Políticas públicas de esporte e lazer no estado do Acre - Brasil. 2014. Tese (Doutorado em Ciência do Desporto) - Universidade do Porto, Porto, Portugal, 2014.

BOUDENS, E. P. J. O financiamento do esporte no primeiro mandato de Lula (20032006). Rio de Janeiro: Usina de Letras, 2007.

BRASIL. Constituição Federal do Brasil de 1988. Brasília, 5 out. 1988. Disponível em: <http://www.planalto.gov.br/ccivil_03/constituicao/constituicaocompilado.htm>. Acesso em: 21 fev. 2017.

BRASIL. Lei $\mathrm{n}^{\circ}$ 9.615, de 24 de março de 1998. Institui normas gerais sobre desporto e dá outras providências. Brasília, 24 mar. 1998. Disponível em: <http://www.planalto.gov.br/ccivil_03/Leis/L9615Compilada.htm>. Acesso em: 21 fev. 2017.

BRASIL. Lei $\mathrm{n}^{\circ}$ 10.672, de 15 de maio de 2003. Altera dispositivos da Lei n. 9.615, de 24 de março de 1998, e dá outras providências. Brasília, 15 mai. 2003. Disponível em: <http://www.planalto.gov.br/ccivil_03/Leis/2003/L10.672.htm>. Acesso em: 21 fev. 2017.

BRASIL._Lei $\mathrm{n}^{\circ}$ 11.438, de 29 de dezembro de 2006. Dispõe sobre incentivos e benefícios para fomentar as atividades de caráter desportivo e dá outras providências. Brasília, 29 dez. 2006. Disponível em: $\quad$ http://www.planalto.gov.br/ccivil 03/ ato20042006/2006/lei/111438.htm>. Acesso em: 15 fev. 2017.

BRASIL. Lei $n^{\circ}$ 13.146, de 6 de julho de 2015. Institui a Lei Brasileira de Inclusão da Pessoa com Deficiência (Estatuto da Pessoa com Deficiência). Brasília, 6 jul. 2015a. Disponível em: <http://www.planalto.gov.br/ccivil_03/_Ato2015-2018/2015/Lei/L13146.htm>. Acesso em: 21 fev. 2017.

BRASIL. Lei no 13.155, 04 de agosto de 2015. Estabelece princípios e práticas de responsabilidade fiscal e financeira e de gestão transparente e democrática para entidades desportivas profissionais de futebol; institui parcelamentos especiais para recuperação de dívidas pela União, cria a Autoridade Pública de Governança do Futebol - APFUT; dispõe sobre a gestão temerária no âmbito das entidades desportivas profissionais; cria a Loteria Exclusiva - LOTEX; altera as Leis n. 9.615, de 24 de março de 1998, 8.212, de 24 de julho de 1991, 10.671, de 15 de maio de 2003, 10.891, de 9 de julho de 2004, 11.345, de 14 de setembro de 2006, e 11.438, de 29 de dezembro de 2006, e os Decretos-Leis n. 3.688, de 3 de outubro de 1941, e 204, de 27 de fevereiro de 1967; revoga a Medida Provisória n. 669, de 26 de fevereiro de 2015; cria programa de iniciação esportiva escolar; e dá outras providências.. Brasília, 4 ago. 2015b. Disponível em: <http://www.planalto.gov.br/ccivil_03/_ato20152018/2015/lei/L13155.htm>. Acesso em: 21 fev. 2017.

CASTRO, S. B. E. de. Políticas públicas para o esporte e lazer e o ciclo orçamentário brasileiro (2004-2011): prioridades e distribuição de recursos durante os processos de elaboração e execução orçamentária. 2016. 211 f. Tese (Doutorado em Educação Física) - Universidade Federal do Paraná, Curitiba, Paraná, 2016.

CAMPOS, M. M. G.. Análise dos gastos em esporte e lazer nos municípios de Minas Gerais nos anos de 2008 a 2012. 2015. 141 f. Dissertação (Mestrado em Sociologia Política) Universidade Federal de Santa Catarina, Florianópolis, 2015. 
COSTA, A.; BEREZOSCHI, E.; RIBEIRO, I.; LIMA, J.; SILVA, M. da; BARCELLOS, T. A socioeconomia da mesorregião da Grande Florianópolis durante o intervalo censitário de 2000 a 2010. Núcleo de Estudos de Economia Catarinense, 2013.

CHRISTENSEN, T. LÆGREID, P.; RONESS P.; RØVIK, K. A. Organization theory and the public sector: instrument, culture and myth. London and New York: Routledge, 2007.

DELGADO, S. C.; MARIN, B. M.; SÁNCHEZ, J. R. Métodos de investigación y análisis de datos en ciências sociales y de la salud. Madrid: Pirámide, 2011

DINIZ, R. S.; SILVA, L. P. da. O ICMS esportivo e o financiamento das políticas municipais de esporte em Minas Gerais. Movimento, v. 22, n. 4, p. 1223-1236, out./dez. 2016.

FERNANDES, C. A. S.; BEZERRA, S. R.. Financiamento de políticas de esporte e lazer em São Luís - MA: o oficial, o dito e o observável. In: ARAUJO, S. M. de; VIANA, R. N. A. (Org.). Esporte e lazer na cidade de São Luís - MA: elementos para a construção de uma política pública. São Luís: EDUFMA, 2008. p. 57-92.

FERRAZ JÚNIOR, T. S. Normas gerais e competência concorrente. Revista da Faculdade de Direito da USP, v. 90, p. 245-251, 1995.

FRANÇA JUNIOR, N. da R.; FRASSON, A. C.; PILATTI, L. A. Lei de incentivo ao esporte: uma forma de inovação na captação de recursos financeiros para o esporte no município de Ponta Grossa - Panorama 2000-2009. Revista Gestão Industrial, v. 6, n. 3, p. 203-217, 2010.

FURTADO, S.; EFFTING, E. R. M.; CASTRO, S. B. E. de; SOUZA, D. L. de. O financiamento do esporte em Santa Catarina: o caso do FUNDESPORTE nos anos de 2011 e 2012. Motrivivência, v. 28, n. 47, p. 145-159, mai. 2016.

MACÁRIO, C. Filipe Mello é o sexto a assumir a Secretaria Estadual de Turismo, Cultura e Esporte em pouco mais de três anos. Diário Catarinense, 9 abr. 2014. Disponível em: <http://dc.clicrbs.com.br/sc/entretenimento/noticia/2014/04/filipe-mello-e-o-sexto-a-assumira-secretaria-estadual-de-turismo-cultura-e-esporte-em-pouco-mais-de-tres-anos4469909.html>. Acesso em: 13 fev. 2017.

MASCARENHAS, F. O orçamento do esporte: aspectos da atuação estatal de FHC a Dilma. Revista Brasileira de Educação Física e Esporte, v. 30, n. 4, p. 963-980, out/dez. 2017.

MATIAS, W. B.; ATHAYDE, P. F.; HÚNGARO, E. M.; MASCARENHAS, F. A Lei de Incentivo Fiscal e o (não) direito ao esporte no Brasil. Movimento, v. 21, n. 1, p. 95-110, jan/mar. 2015.

QUINAUD, R. T. Gestão de recursos financeiros para o esporte na Secretaria de Estado de Turismo, Cultura e Esporte de Santa Catarina: anos 2007-2014. 2015. 112 f. Trabalho de Conclusão de Curso (Bacharel em Educação Física) - Universidade Federal de Santa Catarina, Florianópolis, 2015. 
RUDNICK, L. T.; MATTEDI, M. A. Uma análise da política de descentralização administrativa em Santa Catarina, 2003 - 2009. Revista NECAT, v. 2, n. 4, p. 25-44, jul./dez. 2013.

SANTA CATARINA (Estado). Governo de Santa Catarina. Economia de Santa Catarina é rica e diversificada, 2017. Disponível em: 〈http://www.sc.gov.br/economia>. Acesso em: 13 fev. 2017.

Lei n ${ }^{\circ} 11.348$, de 17 de janeiro de 2000. Dispõe sobre o serviço de loterias e jogos e diversões eletrônicas do Estado de Santa Catarina e dá outras providências, 2000. Disponível em:

<http://www.fesporte.sc.gov.br/antigo/index.php?option=com_content\&view=article\&id=57:1 ei-11348-de-17-de-janeiro-de-2000\&catid=261:legislacao-estadual $>$. Acesso em: 9 fev. 2017.

Decreto $\mathrm{n}^{\circ} 1.309$, de 13 de dezembro de 2012. Regulamenta a Lei ${ }^{\circ} 13.336$, de 8 de março de 2005, e disciplina a celebração de instrumento legal pelo Estado que tenha como objeto o financiamento de programas e projetos culturais, turísticos e esportivos, no âmbito do Sistema Estadual de Incentivo à Cultura, ao Turismo e ao Esporte (SEITEC). Disponível em: <http://legislacao.sef.sc.gov.br/html/decretos/2012/dec_12_1309.htm>. Acesso em: 13 fev. 2017.

Lei $\mathrm{n}^{\mathrm{o}}$ 13.336, de 08 de março de 2005. Institui o Fundo Estadual de Incentivo à Cultura - FUNCULTURAL, o Fundo Estadual de Incentivo ao Turismo - FUNTURISMO, e o Fundo Estadual de Incentivo ao Esporte - FUNDESPORTE, no âmbito do Sistema Estadual de Incentivo à Cultura, ao Turismo e ao Esporte - SEITEC, e estabelece outras providências, 2005. Disponível em:_ <http://www.sol.sc.gov.br/index.php/institucional/legislacao/3-lei13336-2005-rege-recursos-do-seitec/file>. Acesso em: 9 fev. 2017.

Secretaria de Estado de Turismo, Cultura e Esporte. Institucional. 2016. Disponível em:_<http://www.sol.sc.gov.br/index.php/institucional/a-secretaria>. Acesso em: 19 jul. 2016.

SILVA, S. J. da. Análise dos investimentos para o esporte no Brasil (1999-2010). 2012. 124 f. Trabalho de conclusão de curso (Bacharelado em Educação Física) - Universidade Estadual Paulista, Rio Claro, 2012.

SILVA, T. D.; SANTANA, T. A. de; SILVA, R. C. da. O planejamento e a estrutura financeira das políticas públicas de lazer no estado da Bahia. Coleção Pesquisa em Educação Física, v. 14, n. 4, p. 121-130, 2015.

SOUZA, D. O. Destinação de recursos do FUNDESPORTE para atletas catarinenses no período de 2005 a 2015. 2016. 108 f. Trabalho de Conclusão de Curso (Bacharelado em Educação Física) - Universidade Federal de Santa Catarina, Florianópolis, 2016.

STAREPRAVO, F. A.; BASSO, D.; GUIMARÃES, L.; REIS, R. P. dos. Políticas públicas para o esporte e o lazer nas cidades do estado do Paraná. In: MEZZADRI, F. M.; CAVICHIOLLI, F. R.; SOUZA, D. L. de. Esporte e lazer: subsídios para o desenvolvimento e a gestão de políticas públicas. Jundiaí: Fontoura, 2006.

TEIXEIRA, M. R. Esporte, fundo público e pequena política: os reveses de um orçamento (r)emendado. 2016. 114 f. Dissertação (Mestrado em Educação Física) - Universidade de Brasília, Brasília, 2016. 
; MATIAS, W. B.; MASCARENHAS, F. O financiamento do esporte olímpico no Brasil: uma análise do ciclo de Londres (2009-2012). Revista de Ciencias Sociales, n. 31, p. 86-110, 2013.

VAZ, A. F. Políticas públicas para o esporte e o lazer em Santa Catarina: reflexões e considerações. Revista da Educação Física/UEM, v. 12, n. 1, p. 89-96, sem. 2001.

VERONEZ, L. F. C.. Quando o Estado joga a favor do privado: as políticas de esporte após a Constituição Federal de 1988. 2005. 129 f. Tese (Doutorado em Educação Física) Universidade de Campinas, Campinas, 2005.

Recebido em: 24/03/2017

Revisado em: 05/09/2017

Aprovado em: 26/09/2017

Endereço para correspondência:

ricardoquinaud@gmail.com

Ricardo Teixeira Quinaud

Universidade Federal de Santa Catarina.

LAPE- Laboratório de Pedagogia do Esporte,

Trindade, 88040970 - Florianópolis, SC - Brasil, 